\title{
The Magnitude of Failed Induction of Labor and Associated Factors Among Women Delivered at Public Hospitals of Arsi Zone, Southeast Ethiopia, 2020: A Cross-Sectional Study
}

\author{
Mulatu Desta ${ }^{1,2}$ \\ Abdissa Duguma $\mathbb{( D}^{2,3}$
}

'Arsi University, College of Medical Sciences, Department of Nursing, Bokoji, Ethiopia; ${ }^{2}$ Wollega University, Institute of Health Sciences, Department of Nursing, Nekemte, Ethiopia; ${ }^{3}$ Mettu University, College of Medical Sciences, Department of Nursing, Mettu, Ethiopia
Correspondence: Abdissa Duguma Mettu University, P.O. Box 318, Mettu, Ethiopia

Tel +25। 923761502

Email abdiisaa.dhugumaa@meu.edu.et
Background: Failed induction of labor is one challenge in all obstetrics care given all over the world, which increases the incidence and percentage of cesarean sections. It is still a major challenge in both developed and developing countries. This study was significant because it identified the magnitude and associated factors of failed induction of labor.

Objective: To assess the magnitude of failed induction of labor and associated factors among women delivered at public hospitals in the Arsi zone, South East Ethiopia.

Methods: We conducted institutional-based cross-sectional study design in public hospitals in the Arsi zone. We used random-sampling methods, and collected the data using a structured questionnaire and checklist and analysed using a statistical package for social science (SPSS) version 25 software, described and presented data using texts, tables, and charts. We took those variables with a p-value of 0.05 as statistically significant determinants of failed induction of labor.

Results: The magnitude of failed induction of labor was $21.3 \%$. AOR $=8.788,95 \% \mathrm{CI}=$ (2.884-12.397), maternal residence in urban [AOR $=0.356,95 \% \mathrm{CI}:(0.143-0.886)]$, multi para 0.390 times less likely than prime para with odds ratio [AOR $=0.390, \mathrm{CI}:(0.147$, 0.632)], Bishop score before induction started 4 [AOR=5.155, CI: 3.062-7.387]. Indications for IOL: PROM more likely than IUGR [AOR=4.158, 95\% CI: $(2.415$, 9.554)], time from start of induction to deliver less than twelve hours [AOR $=6.511,95 \%$ CI: $(2.477,10.116)]$, were statistically significant determinants of failed induction of labor. Conclusion: Magnitude of failed induction of labor was law in Arsi zone public hospitals when compared to the study done in St. Luke C. Hospital. The factors identified as significantly associated with FIOL in this study were maternal age, maternal residence, prime para, Bishop score four, indications for induction of labor: PROM and post-term pregnancy, and time from the start of induction to deliver, twelve hours.

Keywords: associated factors: failed induction, labor, Arsi zone, Ethiopia

\section{Introduction}

Induction of labor (IOL) is the process of artificially stimulating the uterus to start labor. ${ }^{1}$ Induction of labor is a common obstetric procedure, and performed when the benefits to either the mother or fetus outweigh those of continuing the pregnancy. The indication of Hypertensive Disorders of Pregnancy is eclampsia, Post-term pregnancy, Intra-uterine Fetal Death (IUFD), congenitally abnormal fetus incompatible with life, 
Premature Rupture of Membranes (PROM), RhIsoimmunization, Gestational Diabetes mellitus at term, Intra-uterine Growth Retardation (IUGR), Placental Abruption and minor degree the goal of labor induction must always be to ensure the best possible outcome for the mother and newborn. ${ }^{2}$

Most studies define failed IOL as the impossibility of achieving a vaginal delivery, although many other factors appear during labor that may hinder or prevent a vaginal delivery. ${ }^{3}$

Induction of labor is safe and beneficial in wellselected and properly monitored high-risk pregnancies. ${ }^{4}$ Health care institution carried out Induction of labor when the risk of continuing pregnancy outweighs the benefits. Failed induction of labor is when induced labor fails to cervical dilatation or unable to progress even though there was a good contraction and either of those ends in a caesarean section. ${ }^{5,6}$ vaginal delivery is the goal of the induction process. However, this occurs less often than when a woman's labor spontaneously. ${ }^{7,8}$

It is important to perform Induction of labor (IOL) with caution since the procedure carries the risk of uterine hyper-stimulation, uterine rupture, and non-reassuring fetal heart rate tracing. Failed induction of labor does not show a caesarean section. Health care institution perform induction of labor (IOL) with caution since the procedure carries the risk of uterine hyper-stimulation, uterine rupture, and non-reassuring fetal heart rate tracing. Failed induction of labor does not show a caesarean section. Where possible, they perform IOL at facilities where a caesarean section is relevant. ${ }^{9}$ longer latent labor time only allows a woman to have a full opportunity to have a safe, successful vaginal delivery. The minimum allowed time is $24 \mathrm{hrs}$ after cervical ripening and oxytocin administration before diagnosing a failed induction. ${ }^{10}$

Globally, maternal mortality has declined by $44 \%$ since 1990, with about 303,000 maternal deaths in 2015. The maternal mortality ratio is the highest in the African Region at 542 per $100000 .{ }^{11}$ Globally, the number of neonatal deaths decreased by half from 5 million in 1990 to 2.5 million in 2017. In the African Region, the share of neonatal deaths is $37 \%{ }^{11}$

According to the Ethiopian demographic health survey (EDHS) 2016, maternal mortality in Ethiopia is 412 deaths per 100,000 live births, which is a high and unacceptable death related to world health organization (WHO) standards. ${ }^{12}$
According to the 2019 Ethiopian mini demographic health survey (EMDHS), the neonatal mortality rate in Ethiopia is 30 deaths per 1,000 live births. ${ }^{13}$

In recent decades, more and more pregnant women around the world have undergone IOL to deliver their babies and In developed countries, up to $25 \%$ of all deliveries at term now involve IOL and also in developing countries, the rates are lower, but in some settings, they can be as high as those observed in developed countries.

In the United States, the incidence of labor induction rose 2.5 -fold from $9.5 \%$ in 1991 to $23.8 \%$ in 2015 . At Parkland Hospital, approximately $35 \%$ of labor is induced or augmented. ${ }^{14}$ According to a study done in Nigeria in 2016, the IOL rate was $12.7 \% .^{16}$ The prevalence of failed induction of labor varies from place to place. In the tertiary care hospital in Bhubaneswar, Odisha, India in 2016, the failed IOL was $50.5 \%$. At Paropakar Maternity and Women's Hospital, Thapathali, Kathmandu, Nepal, the failure rate of induction was $23.5 \%$. In Southwest Nigeria in 2016, the failed IOL was $36.5 \%$. In Ethiopia, failed induction of labor: in Wolaita Sodo, South Ethiopia, 26.5\%, in Hawassa Public Health Facilities, Ethiopia, 2015, 17.3\%, in Dessie Referral Hospital in 2017, 19.7\%, in Jimma University Specialized Hospital, failed induction was diagnosed at 21.4\%, and in Wolliso St. Luke, Catholic Hospital, South West Shewa, in 2017, failed IOL was 42\%. ${ }^{3,8,15-20 .}$

Failed induction of labor is the challenge in all obstetrics care given all over the world, which increases the incidence and percentage of C-sections, especially related to failed induction of labor. Most failed inductions ended with caesarean delivery. Caesarean delivery has a risk of adverse maternal outcomes following delivery by caesarean delivery: Overall severe morbidity and mortality, maternal mortality, amniotic fluid embolism, placental abnormalities, urinary incontinence, postpartum depression, and adverse neonatal outcome: Respiratory morbidity increases more than vaginal delivery. ${ }^{21}$ Failed induction of labor is Challenging in all obstetric care being given all over the world, including developed countries.

\section{Methods and Materials}

\section{Study Area and Period}

We conducted this study in selected public hospitals in the Arsi Zone, Oromia regional state, in the South East of Ethiopia. The Arsi Zone is one of the twenty zones found in the Oromia Regional State. Arsi Zone has 25 woreda and four urban administrations (Huruta, Abomsa, 
Dhera, and Bokoji). The total population of the Arsi zone is $3,589,624$, of these, males $1,758,915$ and females 1,830,708. (40) Arsi Zone has one referral and teaching hospital (Arsi University referral and teaching hospital) and seven public (governmental) primary hospitals (Bokoji Primary hospital, Abomsa Primary hospital, Gobessa Primary hospital, Kersa Primary hospital, Robe Dida Primary hospital, Kula Primary hospital, Chancho Primary hospital). The town in the Arsi zone is Asella, which is $175 \mathrm{~km}$ from Addis Ababa. We carried out the study from March 16 to May 16, 2020.

\section{Study Design}

We conducted an institution-based cross-sectional study design.

\section{Population}

\section{Source Population}

The source population of the study was those who gave birth at public hospitals in the Arsi zone, southeast Ethiopia, during the study period.

\section{Study Population}

The study population was those mothers who underwent induction of labor at selected public hospitals in the Arsi zone, southeast Ethiopia, during the study period.

\section{Eligibility Criteria Inclusion Criteria}

All women attended the induction of labor after 28 weeks of gestational age at the selected public hospitals in the Arsi zone during the study period.

\section{Exclusion Criteria}

We excluded Women who referred to higher hospitals for further diagnosis and management in case of emergency after induction of labor started.

\section{Sample Size Determination}

We calculated the sample size by using a single population formula for objective one and calculating the sample size for objective two by using Epi Info version 7.2.2.10 software.

The sample size for the magnitude of failed induction of labor

$$
\mathrm{n}=(\mathrm{Z} / 2) 2 \mathrm{P}(1-\mathrm{P})
$$

Where:

$\mathrm{n}=$ sample size

$\mathrm{Z}=$ standard normal distribution corresponding to significance level at $=0.05 \mathrm{p}=$ proportion of failed induction of labor

we assumed the "P" proportion of failed induction of labor is to be $19.7 \%$, which is taken from a study conducted at Dessie Referral Hospital in 2019. 3

$\mathrm{d}=$ margin of error of $5 \%$

$=3.84(0.197)(0.803)=0.0025$

By adding $10 \%$ of the non-response rate to the sample size, $243+10 \%$ of the calculated sample size will be 243 $+24=267$

The sample size for associated factors of failed induction of labor. We calculated the sample size for objective two by using Epi Info version 7.2.2.10 software. We took the proportion of associated factors from previous studies conducted at Hawassa Public Health Facilities, Ethiopia, in 2015. Advanced maternal age, poor Bishop score, PROM, and greater gestation were significantly associated with failed induction of labor. ${ }^{18}$

We selected the final sample size as objective two (268), which was the largest sample size of the study (Table 1).

\section{Sampling Technique and Procedure}

In the Arsi zone, there is one teaching and referral hospital and seven primary public hospitals (Bokoji hospital, Abomsa hospital, Chancho hospital, Kersa hospital, Kula hospital, Robe Dida hospital, and Gobessa hospital). This

Table I Sample Size Determination for Associated Factors of Failed Induction of Labor Among Women Delivered at Public Hospitals of Arsi Zone, South East, Ethiopia, 2020

\begin{tabular}{|l|l|l|l|l|l|l|l|l|}
\hline S/ & $\begin{array}{l}\text { Determinants Used to Calculate Sample Size } \\
\text { (Variable) }\end{array}$ & P I & P2 & $\begin{array}{l}\text { Sample } \\
\text { Size }\end{array}$ & Power & $\begin{array}{l}\text { I0\% Non-Response } \\
\text { Rate }\end{array}$ & $\begin{array}{l}\% \\
\text { Cl }\end{array}$ & $\begin{array}{l}\text { Total Sample } \\
\text { Size }\end{array}$ \\
\hline I & Advanced maternal Age (age >30) & 33.4 & 13.6 & 144 & 80 & 14 & 95 & 158 \\
2 & Poor Bishop score (Bishop $\leq 5)$ & 23.7 & 6.7 & 142 & 80 & 142.2 & 95 & 156 \\
3 & PROM (yes) & 42 & 25 & 244 & 80 & 24.4 & 95 & 268 \\
4 & Greater gestation (yes) & 41 & 11.1 & 68 & 80 & 6.8 & 95 & 75 \\
\hline
\end{tabular}


study was done at the selected three hospitals from the eight hospitals. The lottery method selected to select the three hospitals, AURTH, Bokoji primary hospital, and Kersa primary hospital. The proportional allocation of samples to each hospital was done based on the average estimated monthly IOL cases of the three hospitals based on the last two months of estimated induction of labor.

Within consecutive two months, there were about 300 inductions of labor. From these, 166 IOL cases from AURTH, 78 IOL cases from Kersa hospital, and 56 induction of labor cases from Bokoji Hospital. Then, we calculated the final sample size and proportionally allocated to those hospitals by considering their last 2 months of induction of labor cases. We collected data consecutively from all women who attended the induction of labor in the study area until we achieved the desired sample size (268) during the study period from March 16 to May 16, 2020.

$\mathrm{n}=$ required sample size (268)

$\mathrm{Ni}=$ Estimated number of inductions of labor in the past 2 months in a specific hospital

$\mathrm{N}=$ Total estimated number of inductions of labor in the past 2 months in all study areas (300) (Figure 1).

\section{Study Variables}

Dependent Variable

Failed induction of labor.

\section{Independent Variables}

Socio-demographic factors of women: Age, residence.

Anthropometry: BMI

Obstetric factors: ANC follow-up, number of parity, gestational age, Bishop Score, blood pressure, weight and sex of the newborn, membrane status at the start of induction.

Oxytocin only, oxytocin with a prior cervical rip, misoprostol only, ARM, Foley catheter.

Indications for induction of labor: Post-term pregnancy, PIH, PROM, Oligohydramnios, Congenital anomaly, IUFD, chorioamnionitis, IUGR

\section{Operational Definitions}

Failed induction of labor: Diagnosed when there has been no cervical change or descent of the presenting part after 6-8 hours of Oxytocin administration and use of the maximum dose for at least one hour, or contraction of 3 in 10

\section{Proportional allocation of the sample to each Hospital}

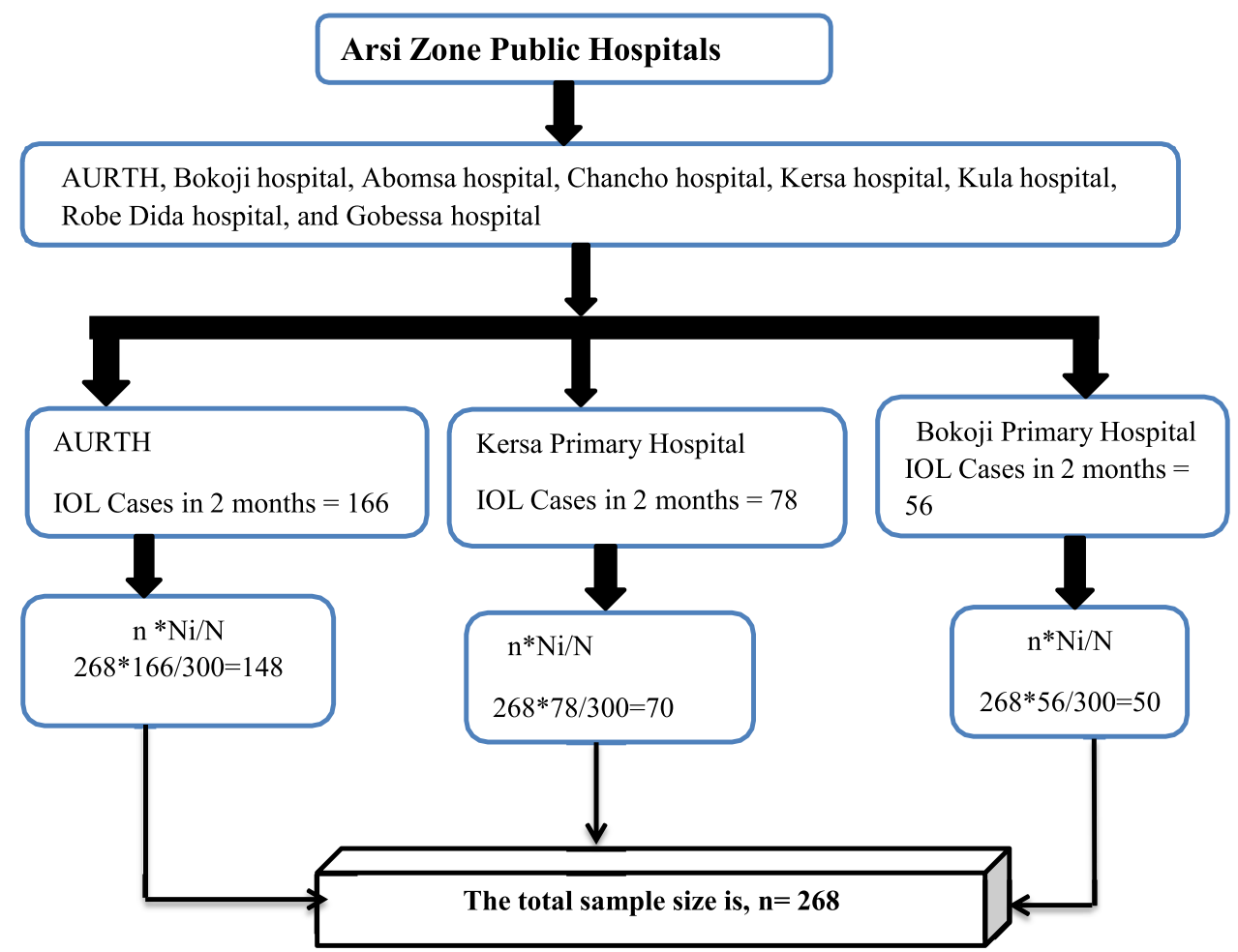

Figure I Schematic representation of the sampling techniques on the Magnitude of Failed Induction of Labor and Associated Factors among Women Attending Induction of Labor in Public Hospitals of Arsi Zone, South Ethiopia, 2020. 
min. (adequate uterine contraction) has not been achieved. $^{6}$

The Bishop score is a method of assessing the cervical condition. Score 4 is unfavorable or unripened.

Score 5-8 is intermediate and score 9 is favorable.

Gestational age: Is the duration of pregnancy calculated from the first day of the last menstrual.

Period.

Parity: A state of previous pregnancy beyond the period of viability.

Post-term pregnancy: Is a pregnancy that has extended to or beyond the gestational age of 42 .

Oligohydramnios: We used the diagnosis of Oligohydramnios based on the records on the patient cards or 294 days from the first day of the last normal menstrual period, or 40 weeks of gestation from the time of conception.

\section{Data Collection Tools and Techniques}

The tools contained a structured interviewer-administered questionnaire, an anthropometry measurement, and a checklist. Structured questionnaire has two parts: Part I socio-demographic factors and Part II obstetric factors. We used the structured questionnaires to collect data containing variables used to assess socio-demographic factors; obstetric factors from the study participants by direct interview. We initially adopted the questionnaire in the English language and then translated into Afaan Oromoo and retranslated back into the English language by a language expert. Since there was no similar questionnaire tool to assess the magnitude and associated factors of failed induction of labor in WHO, UNICEF, or other standardized organizations, the questionnaire was adapted from previous research. ${ }^{3,20}$ We used Cronbach's alpha coefficient check reliability and validity data gathering instrument.

We recorded Anthropometry measurement (BMI) of mothers after delivery of the baby by using a weight and height scale. Finally, we used a checklist that contains obstetric factors, an indication of induction of labor, and methods of indication of labor.

Four Bsc nurses who are working in the study hospital in another ward collected the data and one Bsc midwife supervised during the data collection period. We assigned one data collector for each hospital from the same hospital staff (for Kersa primary hospital and Bokoji primary hospital), and two data collectors for AUTRH from the same hospital staff.

\section{Data Quality Control}

To ensure the quality of data gathered, we made pre-test on 5\% (14 participants) of the sample size at the Abomsa Primary Hospital before the actual data collection started. We made the necessary modifications to the questioners based on the identified gaps. We gave a one-day training for data collectors and supervisors on the objective and relevance of the study, how to gather the appropriate information, procedures for data collection techniques, and the whole contents of the questionnaire before the actual data collection.

The supervisors and principal investigators reviewed and checked for completeness and relevance every day after data collection and they made a thorough check before receiving a questionnaire from each data collector during the whole data collection period. Principal investigators calibrated anthropometry measurements every week by triangulating with standard weight.

\section{Data Analysis and Procedures}

After we checked data for its completeness and consistency, the data cleaned, coded, entered into Epi data version 3.10, and exported to the SPSS version 25-software package for data analysis. The data were analyzed using logistic regression to determine the effect of various factors on the outcome variable. We carried out $\mathrm{A} \mathrm{Bi}$ variable analysis to determine the association of different potential factors. Variables with a p-value of 0.25 were candidates for multivariate logistic regression to control the confounding effect. Those variables with a p-value of less than 0.05 we took as statistically significant determinants of failed IOL In multivariate logistic regression. In addition, we used HosmerLemeshow goodness-of-fit test for checking model fitness with a $p$-value $>0.05$. We presented the data using text, tables, and charts, frequencies, percentages, and medians.

\section{Ethical Consideration}

We took an ethical clearance letter from the Wollega University Ethical Review Board, and received approval letter from selected public hospitals in the Arsi zone. The ethical review board approved to provide Participants under 18 years of age were by the informed consent on their behalf. We explained the procedure and purpose of the study to the study participants and took written informed consent from them. We maintained confidentiality by the patient's name not being included in the questioners and we conducted the study s per the Declaration of Helsinki. 


\section{Results}

\section{Socio-Demographic Characteristics of the Respondents}

In this study, 268 mothers were interviewed with a response rate of $100 \%$, and their documents were reviewed during the study period. The median age of the respondents was 26 years, with a range of 16-45 years. Among respondents' mothers, a greater proportion of 126 (47.0\%) was Muslims, followed by Orthodox Christians $116(43.3 \%)$, and $26(9.7 \%)$ were protestant by religion. The majority of respondents' marital status was 261 $(97.4 \%)$ were married, $5(1.9 \%)$ were single and 2 $(0.7 \%)$ were divorced. Concerning educational level, 95 (35.4\%) completed secondary education, while 79 (29.5\%) were primary and $72(26.7 \%)$ were college or above. Only $22(8.2 \%)$ of respondents were unable to read and write. Regarding monthly income, the majority of respondents (128 (47.3\%) had a monthly income of > 5358-10,015 ETB, 54 (20.1\%) of the monthly income had 1100 ETB. $37(13.8 \%)$ earned > 2344-5358 ETB (Table 2).

Table 2 Sociodemographic Characteristics of Women Who Underwent Induction of Labor from March 16 to May 16, 2020, in Public Hospitals of Arsi Zone in AUTRH, Kersa Primary Hospital \& Bokoji Primary Hospital

\begin{tabular}{|l|l|l|}
\hline Variable & Frequency n=268 & Percentage (\%) \\
\hline Age & 28 & 10.4 \\
$\leq 20$ & 90 & 33.6 \\
$21-25$ & 89 & 33.2 \\
$26-30$ & 52 & 19.4 \\
$31-35$ & 9 & 3.4 \\
$\geq 36$ & \multicolumn{2}{|l|}{} \\
\hline Educational status & 22 & 8.2 \\
\hline Unable to read and write & 79 & 29.5 \\
Primary & 95 & 35.4 \\
Secondary & 72 & 26.9 \\
College or above & \multicolumn{2}{|l}{} \\
\hline Religion & 116 & 43.3 \\
\hline Orthodox & 126 & 47.0 \\
Muslim & 26 & 9.7 \\
Protestant & 212 & 16.8 \\
\hline Ethnic group & 45 & \\
\hline Oromo & \multicolumn{2}{|l|}{} \\
Amhara & \multicolumn{2}{|l|}{} \\
\hline
\end{tabular}

\section{Obstetric Characteristics of the Study}

\section{Participants}

This study shows that of the total participants, more than half (59.7\%) of them were prime para. About 253 (94.4\%) of the participants had ANC follow-up during pregnancy. Out of the total study participants (268), $200(74.6 \%)$ of them had a blood pressure of $90 / 60$ to $140 / 90 \mathrm{mmHg}$ at admission. The majority of participants' gestational age was 163 , (60.8) was a term pregnancy. Among women who underwent induction of labor, $113(42.2 \%)$ had premature rupture of membranes (PROM) (Table 3).

Table 3 Obstetric Characteristics of Women Who Underwent Induction of Labor in Public Hospitals of Arsi Zone from March 16 to May 16, $2020(n=268)$

\begin{tabular}{|c|c|c|}
\hline Variable & Frequency $(n=268)$ & Percentage (\%) \\
\hline \multicolumn{3}{|l|}{ Gestational age } \\
\hline Pre term & 45 & 16.8 \\
\hline Term & 163 & 60.8 \\
\hline Post-term & 60 & 22.4 \\
\hline \multicolumn{3}{|l|}{ Number of Parity } \\
\hline Prime Para & 160 & 59.7 \\
\hline Multipara & 108 & 40.3 \\
\hline \multicolumn{3}{|l|}{ Bishop score } \\
\hline$\leq 4$ is unfavorable & 109 & 30.7 \\
\hline $5-8$ is intermediate & $|3|$ & 48.9 \\
\hline$\geq 9$ is favorable & 28 & 10.4 \\
\hline \multicolumn{3}{|c|}{ Weight of newborn in gram } \\
\hline < 1500 gm. & 10 & 3.7 \\
\hline 1500-2499 gm & 40 & 14.9 \\
\hline 2500-3999 gm. & 212 & 79.7 \\
\hline$\geq 4000 \mathrm{gm}$ & 6 & 2.2 \\
\hline \multicolumn{3}{|l|}{ Sex of the newborn } \\
\hline Male & 147 & 54.9 \\
\hline Female & 121 & 45.1 \\
\hline \multicolumn{3}{|l|}{ Membrane status } \\
\hline Rupture & 113 & 42.2 \\
\hline Intact & 155 & 57.8 \\
\hline \multicolumn{3}{|l|}{ ANC follow up } \\
\hline Yes & 253 & 94.4 \\
\hline No & 15 & 5.6 \\
\hline \multicolumn{3}{|c|}{ Blood pressure at admission } \\
\hline $90 / 60-140 / 90 \mathrm{mmHg}$ & 200 & 74.6 \\
\hline$\geq 140 / 90 \mathrm{mmHg}$ & 68 & 25.4 \\
\hline
\end{tabular}




\section{Indication for Induction of Labor}

In this study, there were different indications of induction of labor. From this, PROM takes the largest account of 100 $(37.3 \%)$. The second-largest indication of induction of labor was pregnancy-induced hypertension 54 (20.1\%), followed by post-term pregnancy 46 (17.2\%), Oligohydramnios 35 (13.1\%), Antepartum hemorrhage (APH) 11 (4.1\%), Chorioamnionitis $10(3.7 \%)$, Intrauterine fetal death (IUFD) 7 (2.6\%), and Congenital anomaly 5 (1.9\%).

\section{Methods of Induction of Labor}

In this study, the most commonly used method of induction was the Foley catheter for ripening, followed by Oxytocin IV infusion 159 (59.3\%). The second commonest method of induction was Oxytocin only 81 (30.2\%), followed by Misoprostol for ripening, then Oxytocin 27 (10.1\%), and ARM and Oxytocin 1. (0.4\%).

\section{The Magnitude of Failed Induction of Labor}

In this study, the magnitude of failed induction of labor in the Arsi zone was 57 (21.3\%). (Figure 2).

\section{$\mathrm{BMI}$}

From the 268 study participants, BMI 18.5 - 24.9 were $185(69 \%), 25-29.9$ were $68(25.4 \%)$ and $<18.5$ were 15. $(5.6 \%)$.

\section{Factors Associated with Failed Induction of Labor in Bivariable Logistic Regression Analysis}

In bivariable analysis, the association of independent variables for failed induction of labor was investigated and seven variables were found significantly associated with failed induction of labor. Those variables were maternal age, maternal residence, Bishop Score before induction started, premature rupture of membrane (PROM), indications for induction of labor, and time from the start of induction to delivery were significantly associated with failed induction of labor (Table 4).

\section{Associated with Failed Induction of Labor in Multivariable Logistic Regression Analysis}

The results of multiple logistic regression models revealed that maternal age, maternal residence, Multi Para, Bishop Score 4, indications for induction of labor: PROM and post-term, and time from the start of induction to delivery were significantly associated with failed induction of labor.

Maternal age at $31-35$ years was 8.788 times more likely to have failed induction of labor than at age 20 years [AOR $=8.788,95 \% \mathrm{CI}=(2.884-12.397)]$. Maternal residence in urban areas is 0.356 times less likely to fail induction of labor than maternal residence in rural areas, with an odds ratio of $[\mathrm{AOR}=0.356,95 \% \mathrm{CI}:(0.143-0.886]$, and Multi Para is 0.390 times less likely than Prime Para with an

\section{Failed Induction of labor}

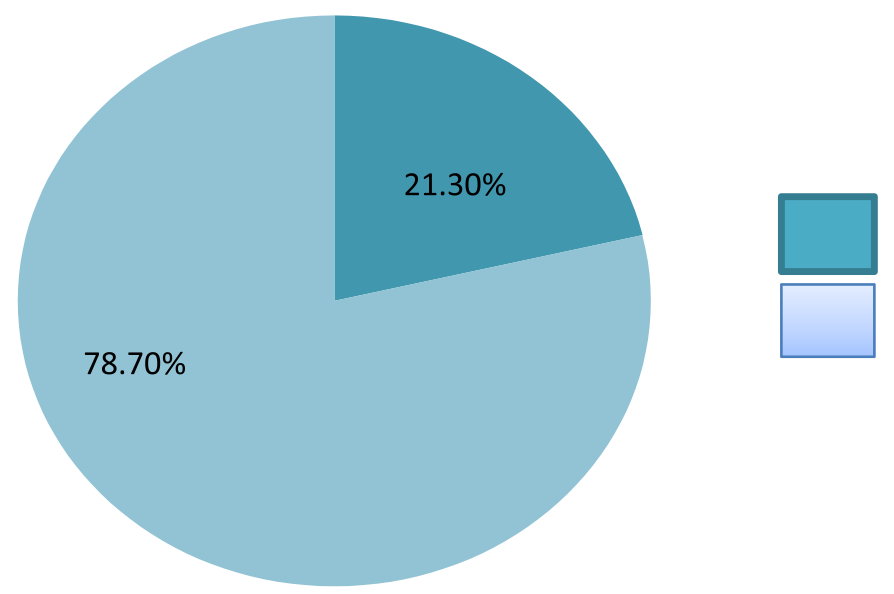

Failed induction

Successful induction

Figure 2 Magnitude of failed induction of labor among women who underwent induction of labor from March 16 to May 16, 2020 , in Arsi zone public hospital, 2020. 
Table 4 Bi-Variable Analysis of Independent Variables Associated Factors for the Failed Induction of Labor Among Women Delivered in the Public Hospitals of the Arsi Zone from March 16 to May 16, 2020 (n=268)

\begin{tabular}{|c|c|c|c|c|}
\hline \multirow[t]{2}{*}{ Variables } & \multicolumn{2}{|c|}{ Failed Induction of Labor (\%) } & \multirow[t]{2}{*}{ COR $(95 \% \mathrm{Cl})$} & \multirow[t]{2}{*}{ P-value } \\
\hline & Yes & No & & \\
\hline \multicolumn{5}{|l|}{ Maternal age } \\
\hline$\leq 20$ & 4 & 24 & I & 1 \\
\hline $21-25$ & 9 & 81 & $0.667(0.189,2.357)$ & 0.529 \\
\hline $26-30$ & 19 & 70 & $1.629(0.504,5.267)$ & 0.415 \\
\hline $31-35$ & 23 & 29 & $4.759(1.445,15.667)$ & $0.01 * *$ \\
\hline$\geq 36$ & 2 & 7 & $1.714(0.258,11.40 I)$ & 0.577 \\
\hline \multicolumn{5}{|l|}{ Marital status } \\
\hline Married & 56 & 205 & $1.639(0.193,13.896)$ & 0.651 \\
\hline Other & 1 & 6 & 1 & I \\
\hline \multicolumn{5}{|l|}{ Education level } \\
\hline Unable to read and write & 2 & 20 & $2.154(0.45 I, 10.29 I)$ & 0.336 \\
\hline Primary & 14 & 65 & $3.97 \mid(0.868,|8.16|)$ & 0.075 \\
\hline Secondary & 27 & 68 & $2.414(0.504,11.56)$ & 0.27 \\
\hline College and above & 14 & 58 & I & I \\
\hline \multicolumn{5}{|l|}{ Monthly income } \\
\hline$\leq 1100$ & 12 & 42 & $0.933(0.436$, I.997) & 0.859 \\
\hline$>1100-2344$ & 6 & 43 & $0.456(0.446, I .175)$ & 0.104 \\
\hline$>2344-5358$ & 9 & 28 & $1.05(0.446,2.469)$ & 0.911 \\
\hline$>5358-1015$ & 30 & 98 & 1 & 1 \\
\hline \multicolumn{5}{|l|}{ Maternal residence } \\
\hline Urban & 18 & 118 & $0.364(0.195,0.677)$ & $<0.001^{* *}$ \\
\hline Rural & 39 & 93 & I & I \\
\hline \multicolumn{5}{|l|}{ ANC follow up } \\
\hline Yes & 54 & 199 & $1.085(0.296,3.984)$ & 0.902 \\
\hline No & 3 & 12 & I & 1 \\
\hline \multicolumn{5}{|l|}{ Parity } \\
\hline Prime Para & 48 & 119 & I & 1 \\
\hline Multi Para & 9 & 92 & $0.505(0.267,0.956)$ & $0.002 * *$ \\
\hline \multicolumn{5}{|l|}{ Gestational age } \\
\hline Pre term & 10 & 39 & I & I \\
\hline Term & 36 & 136 & $1.032(0.47,2.265)$ & 0.937 \\
\hline Post term & 11 & 36 & I.192(0.452,3.14) & 0.723 \\
\hline \multicolumn{5}{|l|}{ Blood pressure at admission } \\
\hline $90 / 60-140 / 90 \mathrm{mmHg}$ & 39 & 161 & $0.673(0.354,1.279)$ & 0.227 \\
\hline$\geq 140 / 90 \mathrm{mmHg}$ & 18 & 50 & 1 & 1 \\
\hline \multicolumn{5}{|l|}{ Sex of neonate } \\
\hline Male & 34 & 113 & $1.282(0.708,2.323)$ & 0.413 \\
\hline Female & 23 & 98 & I & 1 \\
\hline
\end{tabular}

(Continued) 
Table 4 (Continued).

\begin{tabular}{|c|c|c|c|c|}
\hline \multirow[t]{2}{*}{ Variables } & \multicolumn{2}{|c|}{ Failed Induction of Labor (\%) } & \multirow[t]{2}{*}{ COR $(95 \% \mathrm{Cl})$} & \multirow[t]{2}{*}{ P-value } \\
\hline & Yes & No & & \\
\hline \multicolumn{5}{|l|}{ Weight of newborn in gram } \\
\hline$<1500 \mathrm{gm}$ & 2 & 8 & 1 & 1 \\
\hline I500-2499 gm & 7 & 33 & $0.848(0.147,4.888)$ & 0.854 \\
\hline 2500-3999 gm. & 47 & 165 & $1.139(0.234,5.548)$ & 0.872 \\
\hline$\geq 4000$ gm & 1 & 5 & $0.8(0.057,11.298)$ & 0.869 \\
\hline \multicolumn{5}{|l|}{ PROM } \\
\hline Yes & 39 & 74 & $4.01 \mathrm{I}(2.145,7.50 \mathrm{I})$ & $<0.001 * *$ \\
\hline No & 18 & 137 & I & \\
\hline \multicolumn{5}{|l|}{ Indications for induction of labor } \\
\hline Post-term pregnancy & 10 & 36 & $3.5(1.109,11.042)$ & $<0.001 * *$ \\
\hline $\mathrm{PIH}$ & 4 & 50 & $1.008(0.257,3.952)$ & 0.991 \\
\hline PROM & 38 & 62 & $7.723(2.852,20.912)$ & $<0.00 I^{* *}$ \\
\hline *Other & 5 & 63 & 1 & \\
\hline \multicolumn{5}{|c|}{ Bishop score before induction started } \\
\hline$\leq 4$ is unfavorable & 43 & 66 & $7.591(2.304,12.281)$ & $0.006 * *$ \\
\hline $5-8$ is intermediate & 13 & 118 & $2.975(0.373,23.726)$ & $0.204 * *$ \\
\hline$\geq 9$ is favorable & 1 & 27 & I & 1 \\
\hline \multicolumn{5}{|l|}{ Methods of Induction of labor } \\
\hline Oxytocin only & 16 & 65 & $0.753(0.374, I .5 \mid 8)$ & 0.427 \\
\hline $\begin{array}{l}\text { Foley catheter for ripening, then } \\
\text { oxytocin }\end{array}$ & 38 & $12 \mid$ & $0.898(0.3 \mid 3,2.576)$ & 0.842 \\
\hline Misoprostol for ripening, then & 38 & 24 & 1 & 1 \\
\hline Oxytocin & & & & \\
\hline \multicolumn{5}{|c|}{ Time from start of induction to delivery of the baby } \\
\hline Less than 12 hours & 54 & 193 & I & $<0.00 I^{* *}$ \\
\hline 12 or more hours & 3 & 18 & $9.352(5.094,14.040)$ & 1 \\
\hline
\end{tabular}

Notes: *Oligohydramnios, Congenital anomaly, IUFD, Chorioamnionitis, IUG. **Statistical significant associated with p-value $<0.05$.

odds ratio of $[\mathrm{AOR}=0.390,95 \% \mathrm{CI}:(0.147,0.632)$. Those with a Bishop Score before induction started at 4 (unfavorable Bishop Score) were 5.155 times more likely to fail IOL than those with a Bishop Score of 9 (favorable Bishop Score) $[\mathrm{AOR}=5.155,95 \% \mathrm{CI}$ : 3.062-7.387].

Indications for induction of labor (PROM) are 4.15 times more likely to fail induction of labor than those indications are Oligohydramnios, Congenital anomalies, IUFD, Chorioamnionitis, and IUGR [AOR $=4.158,95 \%$ CI: $(2.415,9.554) .6 .511$ times more likely than greater than twelve hours $[\mathrm{AOR}=6.511,95 \% \mathrm{CI}:(2.477,10.116)$ ] (Table 5).

\section{Discussion}

This study gives important information regarding the magnitude of failed inductions of labor and the factors associated with them, such as socio-demographic factors of women, anthropometry, obstetric factors, and methods of induction of labor, and indications for induction of labor.

In this study, the magnitude of the failed induction of labor was 57 (21.3\%). This shows that out of five women who underwent induction into labor, one woman had experienced a failed induction into labor development. This result was in line with the study conducted at Jimma University Specialized Hospital, in which $21.4 \%$ experienced failed induction of labor. 
Table 5 Multivariate Analysis of Independent Variables Associated Factors for the Failed Induction of Labor Among Delivered in the Public Hospitals of Arsi Zone from March 16 to May 16, $2020(n=268)$

\begin{tabular}{|c|c|c|c|c|}
\hline \multirow[t]{2}{*}{ Variables } & \multicolumn{2}{|c|}{ Failed Induction of Labor (\%) } & \multirow[t]{2}{*}{ AOR $(95 \% \mathrm{Cl})$} & \multirow[t]{2}{*}{ P value } \\
\hline & Yes & No & & \\
\hline \multicolumn{5}{|l|}{ Maternal age } \\
\hline$\leq 20$ & 4 & 24 & I & I \\
\hline $21-25$ & 9 & 81 & $2.862(0.464,17.663)$ & 0.257 \\
\hline $26-30$ & 19 & 70 & $7.07 \mid(1.156,43.268)$ & 0.034 \\
\hline $31-35$ & 23 & 29 & $8.788(2.884,12.397)$ & $0.002 * *$ \\
\hline$\geq 36$ & 2 & 7 & $10.268(0.615,11.435)$ & 0.105 \\
\hline \multicolumn{5}{|l|}{ Maternal residence } \\
\hline Urban & 18 & 118 & $0.356(0.143,0.886)$ & $0.026 * *$ \\
\hline Rural & 39 & 93 & 1 & I \\
\hline \multicolumn{5}{|c|}{ Time from start of induction to delivery of the baby } \\
\hline Less than 12 hours & 54 & 193 & $6.511(2.477,10.116)$ & $0.000 * *$ \\
\hline 12 or more hours & 3 & 18 & I & 1 \\
\hline \multicolumn{5}{|l|}{ Parity } \\
\hline Prime Para & 48 & 119 & 1 & 1 \\
\hline Multi Para & 9 & 92 & $0.390(0.147,0.632)$ & $0.004 * *$ \\
\hline \multicolumn{5}{|c|}{ Bishop score before induction started } \\
\hline$\leq 4$ is unfavorable & 43 & 66 & $5.155(3.062,7.387)$ & $0.000 * *$ \\
\hline $5-8$ is intermediate & 13 & 118 & $2.04 I(I .005,8.346)$ & $0.003 * *$ \\
\hline$\geq 9$ is favorable & 1 & 27 & 1 & I \\
\hline \multicolumn{5}{|c|}{ Indications for induction of labor } \\
\hline Post term pregnancy & 10 & 36 & $3.083(2.960,7.368)$ & $0.032 * *$ \\
\hline $\mathrm{PIH}$ & 4 & 50 & $0.747(0.158,3.528)$ & 0.712 \\
\hline PROM & 38 & 62 & $4.158(2.415,9.554)$ & $0.001 * *$ \\
\hline *Other & 5 & 63 & 1 & I \\
\hline
\end{tabular}

Notes: *Oligohydramnios, Congenital anomaly, IUFD, Chorioamnionitis, IUGR. ** Statistically significantly associated with p-value $<0.05$.

These findings are in line with the study done in Hawassa Public Health Facilities, where $17.3 \%$ of women had a failed outcome of IOL. ${ }^{3,18}$

On the other hand, in this study, the rate of failed induction of labor was lower than in the studies done in Bhubaneswar city, Odisha (50.5\%), Southwest Nigeria (36.5\%), and Wolliso St. Luke Catholic Hospital (42\%). This difference may be due to variation in commonly used methods for induction of labor, which was Foley catheter for ripening, then Oxytocin 157 (58.6\%) was the most commonly used method of induction in the study area. While in other cases, misoprostol with other alternatives, like balloon catheters, was used as a common practice. $^{6,15,20 \text {, }}$
The finding of this study shows that mothers aged 31-35 years are 8.788 times more likely to fail induction of labor than mothers aged 20 years. This result is in agreement with the results reported by Hawassa Public Health Facilities, which shows that 9.21 times more likely in advanced maternal age. ${ }^{18}$

This study showed that being multipara was $61 \%$ less likely to fail induction of labor than being prime para with an odds ratio. Similarly, according to the study done in Hawassa Public Health, Facilities and Jimma University Specialized Hospital, failed induction was associated with primiparous women rather than multiparous. ${ }^{18,19}$

According to this study, women living in urban areas are $64.4 \%$ less likely to fail induction than women living in rural areas. Similarly, according to a study done at Dessie Referral 
Hospital, the odds of failed induction were more likely to fail IOL in women who lived in rural areas than in women who lived in urban areas.

This study shows that the time from the start of induction to delivery of the baby is less than twelve hours, more likely to fail IOL than the start of induction to delivery of a baby twelve hours or more than twelve hours. Similarly, Gabbe's seventh edition recommends allowing adequate time for cervical ripening and development of active labor before diagnosing a failed induction helps to minimize the magnitude of the failed IOL. ${ }^{7}$

The finding of this study shows that an unfavorable Bishop 20 is more likely than a favorable Bishop score. Similarly, the study done in Hawassa Public Health Facilities shows an unfavorable Bishop is more likely than a favorable Bishop Score. ${ }^{18}$

The finding of this study show that the odds of failed induction were more likely in women with post-term pregnancies than in others. Similarly, a study done in a health resource-poor setting shows that the risk of failed induction of labor increases $(p=0.0001)$ with post-term pregnancy than with preterm and post-term pregnancy. ${ }^{22}$

These studies reveal that premature rupture of the membrane increases the chance of failed induction of labor more than an intact membrane. This study is in line with a study done at Assam Medical College and Hospital, Dibrugarh, Assam, India, which shows that being PROM increases the chance of failed induction of labor. ${ }^{22}$

\section{Strength and Limitation \\ Strength of the Study}

- Add BMI variable on the study which was not previously done in our country

- Use of primary data

- A high response rate of respondents

\section{Limitation of the Study}

- Recall Bias of the mothers during giving the data.

- Since this study was a cross-sectional study design, the nature of the study may be difficult to ascertain the causal relationship between the study variables.

\section{Conclusion}

Based on this finding, it was concluded that the overall Arsi zone public hospital magnitude of failed induction of labor was $23 \%$. Failed induction of labor in this study is relatively the same as failed induction of labor reported by other studies from different countries. The factors identified to be significantly associated with failed induction of labor in this study were: maternal age, maternal residence, multipara, Bishop Score before induction started, indications for induction of labor: PROM and post-term pregnancy, and time from the start of induction to delivery were significantly associated with failed induction of labor.

\section{Abbreviations}

AOR, Adjusted Odds Ratio; APGAR, Appearance, Pulse, Grimace, Activity, Respiration; ARM, Artificial Rupture of Membranes; AUTRH, Arsi University Referral and Teaching Hospital; BMI, Body Mass Index; BP, Blood Pressure; CS, Cesarean Section; EMDHS, Ethiopian Mini Demography Health Survey; ETB, Ethiopian Birr; FOIL, Failed induction of labor; IOL, Induction of Labor; IUFD, Intra Uterine Fetal Death; IUGR, Intrauterine Growth Restriction; NICU, Neonatal Intensive Care Unit; OR, Odds Ratio; PIH, Pregnancy Induced Hypertension; PPROM, Preterm Premature Rupture of the Membranes; PROM, Premature Rupture of the Membranes; SDG, Sustainable Development Goal; SPSS, Statistical Package for Social Science; VD, Vaginal Delivery; W/H2, Weight over height square; WHO, World Health Organization.

\section{Data Sharing Statement}

We can affirm that the data we have used for this research is available on our hands and we can provide it when it is needed by this journal.

\section{Ethics Approval and Informed Consent}

An ethical clearance letter was taken from Wollega University Ethical Review Board. The approval letter was obtained from selected public hospitals of the Arsi zone. The procedure and purpose of the study were explained to the study participant and written informed consent was taken from participants.

\section{Consent for Publication}

We, the undersigned, gave our consent for the publication to be published in the above Journal and Article. We confirm that we have seen and been allowed to read both the Material and the Article. We understand that journals may be available in both print and on the internet, and will be available to a broader audience through marketing channels and other third parties. Therefore, anyone can read material published in the Journal. 


\section{Acknowledgments}

We would like to thanks Wollega University, the institute of health sciences, the School of nursing, and the midwifery Department of nursing for giving us the chance to conduct this study and financial support. We would also like to express our heartfelt gratitude to the participant of this study. We also would like to thanks our advisors Mr. Reta Tsegaye (BSc, MSc, Assistance Professor) and Dr. Aaga Wakgari (MD, Assistance professor in Obstetrics and Gynecology) for their constructive advice, support, valuable comments, and suggestions during the process of conducting this study.

\section{Author Contributions}

Both authors made a significant contribution to the work reported, whether that is in the conception, study design, execution, and acquisition of data, analysis, and interpretation, or all these areas; took part in drafting, revising, or critically reviewing the article; gave final approval of the version to be published; have agreed on the journal to which the article has been submitted; and agreed to be accountable for all aspects of the work.

\section{Funding}

Wollega university institute of health science has funded us with twenty-five thousand (25000) Ethiopian birr.

\section{Disclosure}

The authors report no conflicts of interest for this work.

\section{References}

1. World Health Organization. WHO Recommendations: Induction of Labor at or Beyond Term.Geneva: World Health Organization; 2018. Available from: https://www.ncbi.nlm.nih.gov/books/NBK535795/. Accessed September 14, 2021.

2. Rajput DA, Bhalerao MV. Induction of labor: a review. J Midwifery Women's Health. 2014;24(11):1057-1064.

3. Dilnessa T, Temesgen K, Workie A. The proportion of failed induction of labour and associated factors among women undergoing induction of labour in Dessie referral hospital: northeast Ethiopia a cross-sectional study. Asian J Preg Childbirth. 2019;2(3):1-13.

4. Lawani OL, Onyebuchi AK, Iyoke CA, Okafo CN, Ajah LO. Obstetric outcome and significance of labour induction in a health resource poor setting. Obstet Gynecol Int. 2014,2014:419621. doi:10.1155/2014/ 419621

5. West HM, Jozwiak M, Dodd JM. Methods of term labor induction for women with a previous cesarean section. Cochrane Database Syst Rev. 2017;2017(6):CD009792. doi:10.1002/14651858.CD009792.pub3
6. Segni H, Negussie D. Obstetric management guideline for Jimma University Specialized Hospital (JUSH); In use since Sept.2010. 2010;1-302. Available from: https://www.researchgate.net/publication/ 275029069_Obstetric_management_guideline_for_Jimma_University_ Specialized_Hospital_JUSH_In_use_since_Sept2010. - Accessed September 20, 2021

7. Niebly JR. Consult E. In: Gabbe S, Niebyl J, Simpson J, editors. Obstetrics Normal and Problem Pregnancies. 7th ed. Elsevier; 2017:513-518.

8. Tripathy P, Pati T, Baby P, Mohapatra SK. Prevalence and predictors of failed induction. Int J Pharm Sci Rev Res. 2016;39(2):189-194.

9. Sharada K, Warrier H, Reddy AK, Thulasi P. Misoprostol and Oxytocin in the induction of labor. Int Arch Integr Med. 2018;5 (3): $97-105$.

10. Ahmed I. Factors associated with failed induction of labor in a secondary care hospital. J Pak Med Assoc. 2012;62(January):6-10.

11. World Health Organization. The Global Strategy for Women's, Children's and Adolescents' Health (2016-2030); 2015:1-108. Available from: https://www.who.int/life-course/partners/global-strat egy/globalstrategyreport2016-2030-lowres.pdf. Accessed September 20, 2021.

12. Federal Democratic Republic of Ethiopia. Demographic and Health Survey; 2016. Available from: https://dhsprogram.com/pubs/pdf/ FR328/FR328.pdf. Accessed September 14, 2021.

13. Ethiopian Public Health Institute and ICF. Ethiopia; Mini Demographic and Health Survey; 2019. Available from: https:// dhsprogram.com/pubs/pdf/FR363/FR363.pdf. Accessed September 14, 2021.

14. Cunningham FG, Leveno KJ, Bloom SL. Williams Obstetrics. 25th ed. McGraw; 2017.

15. Bello FA, Akinyotu OO. Predictors of successful induction of labour at a tertiary obstetric service in Southwest Nigeria.Trop $J$ Obstet Gynaecol. 2016;33(2):143-148. doi:10.4103/0189-5117.192213

16. Acharya T, Devkota R. Outcome of misoprostol and oxytocin in the induction of labor. SAGE Open Med. 2017;5:1-7. doi:10.1177/ 2050312117700809

17. Bekru ET, Yirdaw BE. Success of labor induction institution-based cross-sectional study Wolaita Sodo, South Ethiopia. Int J Nurs Midwifery. 2018;10(12):161-167. doi:10.5897/IJNM2018.0303

18. Hurissa BF, Geta M, Belachew T. Prevalence of failed induction of labor and associated factors among women delivered in Hawassa Public Health Facilities, Ethiopia, 2015. J Women's Health Care. 2015;4(5):1000253. doi:10.4172/2167-0420.1000253

19. Girma W, Tseadu F, Wolde M. Outcome of Induction and Associated Factors among Term and Post- Term Mothers Managed at Jimma University Specialized Hospital: a Two Years ' Retrospective Analysis. Ethiop J Health Sci. 2016; 26(2):121-130.

20. Abdulkadir Y, Dejene A, Geremew MA, Dechasa B. Induction of Labor Prevalence and Associated Factors for Its Outcome at Wolliso St. Luke, Catholic Hospital, South West Shewa, Oromia. Intern Med.2017;7(5): 1000255. doi:10.4172/2165-8048.1000255

21. Bassetty KC, Ahmed RD. Failed induction of labor (IOL): an overview regarding obstetric outcome and its significance in a health resource poor setting over a period of 11 months. Int $J$ Reprod Contracept Obstet Gynecol. 2017;6(8):3646-3650. doi:10.18203/ 2320-1770.ijrcog20173502

22. Bassetty KC, Ahmed RD. Failed induction of labor (IOL): an overview regarding the obstetric outcome and its significance in a health resource-poor setting for 11 months. Int J Reprod Contraception Obstet Gynecol. 2017;6(8):3646. doi:10.18203/2320-1770.ijrcog20173502 


\section{Publish your work in this journal}

The International Journal of General Medicine is an international, peer-reviewed open-access journal that focuses on general and internal medicine, pathogenesis, epidemiology, diagnosis, monitoring and treatment protocols. The journal is characterized by the rapid reporting of reviews, original research and clinical studie across all disease areas. The manuscript management system is completely online and includes a very quick and fair peer-review system, which is all easy to use. Visit http://www.dovepress.com/ testimonials.php to read real quotes from published authors.

Submit your manuscript here: https://www.dovepress.com/international-journal-of-general-medicine-journal 